\title{
Evaluation of long-term effect of tuberculosis chemoprophylaxis in patients using anti tumor necrosis factor alpha agents
}

\author{
๑Ş Şeyma Başlılar', @Mehtap Aydın² \\ ${ }^{1}$ University of Health Sciences, Ümraniye Training and Research Hospital, Department of Chest Diseases, İstanbul, Turkey \\ ${ }^{2}$ University of Health Sciences, Ümraniye Training and Research Hospital, Department of Infectious Diseases, İstanbul, Turkey
}

Cite this article as: Başlılar Ş, Aydın M. Evaluation of long-term effect of tuberculosis chemoprophylaxis in patients using anti tumor necrosis factor alpha agents. Anatolian Curr Med J 2021; 3(2); 115-119.

\begin{abstract}
Aim: There is an increased risk of tuberculosis (TB) in patients with rheumatoid diseases (RD) treated with antitumor necrosis factor (TNF) alpha agents. Screening and, if necessary, chemoprophylaxis is recommended in patients undergoing anti TNF alpha treatment. This study aimed to determine the incidence of active TB due to long term anti TNF alpha usage in patients with $\mathrm{RD}$ and to evaluate the effectiveness of tuberculosis chemoprophylaxis regimen.

Material and Method: Patients treated with anti TNF alpha agents for more than 5 years with RDs were evaluated retrospectively. Demographic and clinical characteristics, use of chemoprophylaxis, laboratory tests before and after anti TNF alpha treatment and development of TB were examined.

Findings: A total of 150 patients (79 male [52.7\%], 71 female [47.3\%]) with a mean age of $45 \pm 13$ years were evaluated. The tuberculosis rate over 5 years follow up was found as $1.3 \%$. One male developed pulmonary TB 5 years and 1 female developed miliary TB 10 years after the beginning of anti-TNF alpha therapy despite chemoprophylaxis with isoniazid. The mean number of neutrophils, lymphocytes $(\mathrm{p}<0.05)$ and the $\mathrm{N} / \mathrm{L}$ ratio was significantly decreased after anti TNF alpha treatment $(\mathrm{p}<0.0001)$. Conclusion: In an RD patient treated with anti TNF alpha agents, the risk of TB should be kept in mind even after 10 years. Regular monitoring should be considered for long term TNF antagonist therapy.
\end{abstract}

Keywords: Anti TNF alpha, tuberculosis, isoniazid, chemoprophylaxis, long term effectiveness.

\section{INTRODUCTION}

The role of TNF alpha in the pathogenesis of rheumatic diseases (RD) is immunomodulation, particularly as a proinflammatory cytokine (1).

The biologic antagonists of TNF alpha (anti TNF alpha), represent a major advance in the management of $\mathrm{RD}$. However, an increased risk of tuberculosis (TB) in patients with RD who treated with anti TNF alpha agents has been demonstrated by several researchers (2,3). 2 -fold elevated risk of TB by anti TNF alpha agents was reported at a systematic meta-analysis of randomized clinical trials (4). Guidelines recommends implementation of screening and, if necessary, chemoprophylaxis in patients undergoing anti TNF alpha treatment (5). Several studies reported higher incidence of $\mathrm{TB}$ among $\mathrm{RD}$ patients who treated with anti TNF alpha than without anti TNF alpha, despite chemoprophylaxis $(6,7)$. This study aimed to determine the incidence of active TB due to anti TNF alpha usage in patients with $\mathrm{RD}$ for a long time period and to evaluate the effectiveness of an antituberculosis chemoprophylaxis regimen.

\section{MATERIAL AND METHOD}

This retrospective study included patients with RDs (Crohn's disease, rheumatoid arthritis, ankylosing spondylitis, ulcerative colitis and psoriatic arthritis) that treated with anti TNF- $\alpha$ agents, admitted to University of Health Sciences, Ümraniye Training and Research Hospital, Chest Diseases Outpatient Clinic between January 10, 2010 and January 10,2020. The study was approved by University of Health Sciences, Ümraniye Training and Research Hospital Ethics Committee (235/ June 11, 2020). The trial was conducted in accordance with the Helsinki Declaration principles. Clinical, radiological and laboratory information were collected from our hospital's medical database. Each patient's data 
were observed for at least 5 years from the beginning of assignment, and patient's data were analyzed to evaluate the risk of TB development.

Demographic characteristics including age and gender, and clinical characteristics including $\mathrm{RD}$ and development of $\mathrm{TB}$ were examined. In order to determine active and latent $\mathrm{TB}$, all patients had undergone a tuberculin skin test (TST) and a posteroanterior chest radiograph (CXR). According to national tuberculosis guideline, patients with latent tuberculosis infection (LTBI) received isoniazid (INH, $\mathrm{H}, 5 \mathrm{mg} / \mathrm{kg}$ with maximum dose $300 \mathrm{mg} / \mathrm{d}$ ) for 9 months. LTBI was diagnosed as having a positive PPD $(\geq 5 \mathrm{~mm})$ result or a positive quantiferon TB test in presence of a negative PPD (8). Anti TNF alpha treatment was started 1 month later than TB chemoprophylaxis.

\section{Statistical Analysis}

Patient data collected in the study were analyzed with the IBM Statistical Package for the Social Sciences (SPSS) for Windows 21.0 package program (Statistical Package for the Social Sciences, Chicago, IL, USA).

Discrete data were given as frequency and percentage. The mean \pm Standard deviation for continuous data was given as a descriptive value. The repeated measures of ANOVA test was used for evaluation of pre and posttreatment data. The results were considered statistically significant when the p-value was less than 0.05 .

\section{RESULTS}

Among the 150 patients included in this study, 79 were male $(52.7 \%), 71$ were female $(47.3 \%)$, and the mean age was $45 \pm 13$ years. $63(42.0 \%)$ had Crohn's disease, $41(27.3 \%)$ had rheumatoid arthritis, $33(22.0 \%)$ had ankylosing spondylitis, $6(4.0 \%)$ had ulcerative colitis and $7(4.7 \%)$ psoriatic arthritis.

There were 18 patients with hypertension (12\%), 8 patients with diabetes mellitus (5.3\%), 3 patients with asthma (2\%), 2 patients with chronic obstructive pulmonary disease and 3 patients with coronary arterial disease.

Sixty six (44\%) of the patients received adalimumab, 35 $(23.3 \%)$ of the patients received infliximab, $17(11.3 \%)$ of the patients received etanercept, $12(8.0 \%)$ of the patients received golimumab, $10(6.7 \%)$ of the patients received certolizumab. Ten patients (6.7\%) received other anti TNF alpha agents such as tofacitinib, vedolizumab and abatacept. Additionally 61 (40.7\%) of the patients received immunosuppressive drugs (Table 1). The mean number of peripheral blood cell counts and neutrophil/lymphocyte $(\mathrm{N} / \mathrm{L})$ ratio before and after anti TNF alpha treatment was shown in Table 2. The mean number of leukocytes were similar before and after treatment ( $p>0.05)$ while the mean number of neutrophils and lymphocytes were decreased significantly $(\mathrm{p}<0.05)$. The N/L ratio was significantly decreased after anti TNF alpha treatment $(2.83 \pm 1.819$ and $2.19 \pm 1.392$ respectively, $\mathrm{p}<0.0001)$.

Table 1. Clinical, demographic and laboratory features of the patients

\begin{tabular}{|c|c|c|}
\hline & & $\begin{array}{c}\mathbf{n}(\%) \text { or } \\
\text { mean } \pm \mathrm{SD}^{*}\end{array}$ \\
\hline \multirow{2}{*}{ Sex } & Female & $71(47.3)$ \\
\hline & Male & $79(52.7)$ \\
\hline \multicolumn{2}{|l|}{ Age (years) } & $45 \pm 13$ \\
\hline \multicolumn{2}{|c|}{ Follow up duration (years) } & $6 \pm 1$ \\
\hline \multirow{5}{*}{ Rheumatoid disease } & Crohn's disease & $63(42.0)$ \\
\hline & Rheumatoid Arthritis & $41(27.3)$ \\
\hline & Ankylosing Spondylitis & $33(22.0)$ \\
\hline & Ulcerative colitis & $6(4.0)$ \\
\hline & Pseuriatic arthritis & $7(4.7)$ \\
\hline \multirow{8}{*}{$\begin{array}{l}\text { Anti-TNF alpha } \\
\text { agent }\end{array}$} & Adalimumab & $66(44.0)$ \\
\hline & Sertolizumab & $10(6.7)$ \\
\hline & Etanercept & $17(11.3)$ \\
\hline & Infliximab & $35(23.3)$ \\
\hline & Golimumab & $12(8.0)$ \\
\hline & Tofacitinib & $4(2.7)$ \\
\hline & Vedolizumab & $2(1.3)$ \\
\hline & Abatacept & $4(2.7)$ \\
\hline \multicolumn{2}{|c|}{ INH chemoprophylaxis } & $124(82.6)$ \\
\hline \multirow{2}{*}{ TST } & Negative (0-4 mm) & $28(18.7)$ \\
\hline & Positive ( $\geq 5 \mathrm{~mm})$ & $122(81.3)$ \\
\hline \multirow{3}{*}{ Quantiferon TB } & Not performed & $136(90.7)$ \\
\hline & Negative & $12(8.0)$ \\
\hline & Positive & $2(1.3)$ \\
\hline \multicolumn{2}{|c|}{ Developed active TB } & $2(1,3)$ \\
\hline \multirow{10}{*}{$\begin{array}{l}\text { Additional } \\
\text { immunosuppressive } \\
\text { agent }\end{array}$} & None & $89(59.3)$ \\
\hline & $\mathrm{OCS}^{* *}$ & $6(4.0)$ \\
\hline & OCS+Leflunomide & $5(3.3)$ \\
\hline & $\mathrm{OCS}+\mathrm{MTX}^{* * *}$ & $7(4.7)$ \\
\hline & OCS+azathioprine & $1(0.7)$ \\
\hline & Leflunomide & $4(2.7)$ \\
\hline & Leflunomide+MTX & $1(0.7)$ \\
\hline & MTX & $6(4.0)$ \\
\hline & Azathioprine & $27(18.0)$ \\
\hline & OCS+Leflunomide+MTX & $4(2.7)$ \\
\hline
\end{tabular}

Table 2. Laboratory values before and after anti TNF alpha treatment

\begin{tabular}{|lccc|}
\hline & $\begin{array}{c}\text { Pre-treatment } \\
(\text { mean } \pm \text { SD })\end{array}$ & $\begin{array}{c}\text { Post-treatment } \\
(\text { mean } \pm \text { SD })\end{array}$ & p value \\
\hline $\begin{array}{l}\text { Number of } \\
\text { leukocytes } \times 10^{3} / \mathrm{ml}\end{array}$ & $9758 \pm 17743$ & $7604 \pm 2178$ & 0.612 \\
$\begin{array}{l}\text { Number of } \\
\text { neutrophils } \times 10^{3} / \mathrm{ml}\end{array}$ & $5367 \pm 2219$ & $4440 \pm 1747$ & 0.013 \\
$\begin{array}{l}\text { Number of } \\
\text { lymphocytes } \times 10^{3} / \mathrm{ml}\end{array}$ & $2225 \pm 814$ & $2415 \pm 950$ & 0.003 \\
$\mathrm{~N} / \mathrm{L}^{*}$ ratio & $2.83 \pm 1.819$ & $2.19 \pm 1.392$ & 0.0001 \\
\hline N/L: Neutrophil/lymphocyte. & & & \\
\hline
\end{tabular}


Among the 150 patients, LTBI was diagnosed in 124 cases (122 had a positive PPD and 2 had a negative PPD but positive quantiferon test result) and were administered isoniazid. Two over 124 patients with LTBI developed active TB, one developed pulmonary TB 5 years after and one developed military TB 10 years after the beginning of anti TNF alpha therapy. Both of the patients had received chemoprophylaxis. Anti TNF alpha therapy was discontinued in patients immediately after the diagnosis of active TB. The characteristics of these patients are shown in the Table 3.

\begin{tabular}{|lcc|}
\hline \multicolumn{3}{|c|}{ Table 3. Characteristics of patients with active TB } \\
\hline Characteristics & Patient 1 & Patient 2 \\
\hline Age, years & 38 & 49 \\
Sex & Male & Female \\
Rheumatoid disease & Crohn's disease & Crohn's disease \\
Medication for RD & Adalimumab & Infliximab \\
TST (mm) & 9 & 4 \\
Quantiferon TB & Not perfomed & Positive \\
Chemoprophylaxis regimen & INH 9 months & INH 9 months \\
Site of active TB & Pulmonary & Miliary \\
Interval to active TB & 5 years & 10 years \\
Immunosuppressive drug & Yes (MTX) & No \\
$\begin{array}{l}\text { Number of lymphocytes, } \\
\text { pre-treatment, } \times 10^{3} / \mathrm{ml}\end{array}$ & 3410 & 780 \\
$\begin{array}{l}\text { Number of neutrophils, } \\
\text { pre-treatment, } \times 10^{3} / \mathrm{ml}\end{array}$ & 8690 & 4770 \\
N/L ratio, pre-treatment & 2.54 & 6.11 \\
$\begin{array}{l}\text { Number of lymphocytes, } \\
\text { post-treatment, } \times 10^{3} / \mathrm{ml}\end{array}$ & 3110 & 1150 \\
$\begin{array}{l}\text { Number of neutrophils, } \\
\text { post-treatment, } \times 10^{3} / \mathrm{ml}\end{array}$ & 4220 & 3820 \\
N/L ratio, post-treatment & 1.35 & 3.32 \\
\hline MTX: Methotrexate & & \\
\hline
\end{tabular}

\section{DISCUSSION}

To our knowledge this study is unique for the long duration of follow up the $\mathrm{RD}$ patients with anti TNF alpha therapy.

Adalimumab, infliximab and etanercept has been licensed and widely used in the treatment of rheumatoid diseases in our country. A nationwide study showed 6 -fold increase in relative TB risk due to 2 years anti TNF alpha use in rheumatologic diseases and 4. 7-fold during 1 year anti TNF alpha therapy (9). In our study the patients who received anti TNF alpha therapy were followed at routine quarterly intervals for long term (510 years). Tuberculosis was diagnosed in two (1.3\%) of 150 patients who were followed up regularly during anti TNF alpha treatment. One of the patient was on the 5th year of treatment and the other one was on the 10th year of treatment. This rate is higher than the incidence of tuberculosis in our country (8). Hanta et al. (10) reported 3 patients who were diagnosed with tuberculosis in the 3-year follow-up of 192 patients with RA, AS and PSA. The rate of active TB in this study (1.5\%) was similar with our findings (1.3\%). However, our follow up duration was longer than these studies.

Age older than 60 years was independent risk factor for $\mathrm{TB}$ among patients with anti TNF alpha treatment in previous studies that were higher than that in our study (11-13).

Tuberculosis is more common among men than women worldwide (14). In our study one of the patient was male and one of the patients was female.

It is reported in the systematic meta-analyses that RA patients treated with anti TNF alpha had increased risk of TB (15). While several studies reported no significantly increased risk of TB infection when anti TNF alpha were used to manage patients with Crohn's disease, a systematic meta-analysis found that the risk of TB was increased by using anti TNF alpha inhibitors in patients with Crohn's disease (16-18).

Most of our patients that we follow up, had Crohn's disease. The reason of the detection of TB, only in Crohn's disease patients, may be due to the clustering of the Crohn's disease cases in our study. The increased number of TB cases among Crohn's disease patients in our study needs to be further addressed in future studies.

The risk of TB according to the classes of anti TNF alpha drugs was found to different. A higher TB risk with infliximab or adalimumab was reported than with etanercept (19). In a study published in 2007 it was found that the risk of TB of patients with RA was 8.9 times higher than the general population. This rate was found to be 30.1 times higher in patients with RA who were treated with infliximab (20). In our study, the patient who received etanercept was diagnosed with miliary tuberculosis.

Latent TB was reactivated despite a chemoprophylaxis in two $(1.3 \%)$ of the patients.

Our national TB guideline recommends 9 months of isoniazid prophylaxis for the treatment of latent $\mathrm{TB}$ infections defined as having a PPD result $\geq 5 \mathrm{~mm}$ or a positive interferon gamma release test such as quantiferon $\mathrm{TB}$, prior to initiation of anti TNF alpha therapy. It was pointed out that the TB chemoprophylaxis could be effective for as long as 19 years and it must be repeated in case of a close contact with active tuberculosis patient (8). The two patients developed active TB denied a close contact with an active TB cases, so the INH prophylaxis was not repeated.

Researchers reported the active $\mathrm{TB}$ cases despite INH prophylaxis during maximum 3 years follow up. Sichletidis et al. (21) found that eleven patients developed active TB among 45 patients. In another study of the total 
of 255 patients whom were diagnosed with latent TB, 5 patients developed active TB after LTBI treatment and the maximum duration of time to TB after anti TNF alpha initiation was 73,2 months (22).

It was previously shown that the decreased number of lymphocytes is a risk factor for developing TB $(23,24)$. Berhane et al. (25) reported that $\mathrm{N} / \mathrm{L}$ ratio over 2.7 is a predictive parameter in diagnosis of pulmonary tuberculosis. One of our patient developed TB had a $\mathrm{N} / \mathrm{L}$ ratio over 2.7 but the other did not. In our study the mean number of neutrophils, lymphocytes and N/L ratio was decreased significantly $(\mathrm{p}<0.05)$ after anti TNF alpha treatment but as the number of patients developed TB was small we could not show a relation between neither number of peripheral blood cells nor $\mathrm{N} / \mathrm{L}$ ratio and developing TB.

Compared to the studies in the literature, we observed the patients for longer duration. TB developed in two patients among 124 patients who received INH prophylaxis. It is possible that long-term anti TNF alpha therapy may predispose patients to both de novo TB infection and reactivation of latent TB. Periodic regimens may be more effective for these patients.

Limitations: Only 2 of 150 patients developed tuberculosis so the risk for developing active TB could not be analyzed.

\section{CONCLUSION}

As a result of this study, we want to draw attention to the risk of $\mathrm{TB}$ development in an $\mathrm{RD}$ patient without latent $\mathrm{TB}$. In an $\mathrm{RD}$ patient without latent $\mathrm{TB}$, the risk of TB should be kept in mind even after 10 years. Regular monitoring should be considered for long term TNF antagonist therapy.

\section{ETHICAL DECLARATIONS}

Ethics Committee Approval: The study was approved by University of Health Sciences, Ümraniye Training and Research Hospital Ethics Committee (235/June 11,2020). Informed Consent: Because the study was designed retrospectively, no written informed consent form was obtained from patients.

Referee Evaluation Process: Externally peer-reviewed.

Conflict of Interest Statement: The authors have no conflicts of interest to declare.

Financial Disclosure: None.

Author Contributions: All of the authors declare that they have all participated in the design, execution, collection and analysis of the data and that they have approved the final version.

\section{REFERENCES}

1. Choy EHS, Panayi GS. Cytokine pathways and joint inflammation in rheumatoid arthritis. N Engl J Med 2001; 344: 907- 15.

2. Wolfe F, Michaud K, Anderson J, Urbansky K. Tuberculosis infection in patients with rheumatoid arthritis and the effect of infliximab therapy. Arthritis Rheum 2004; 50: 372-9.

3. Cantini F, Niccoli L, Goletti D. Adalimumab, etanercept, infliximab, and the risk of tuberculosis: data from clinical trials, national registries, and postmarketing surveillance. J Rheumatol 2014; 41: S47-S55.

4. Zhang Z, Fan W, Yang G, et al. Risk of tuberculosis in patients treated with TNF- $\alpha$ antagonists: a systematic review and metaanalysis of randomised controlled trials. BMJ Open 2017; 7: e012567.

5. Nordgaard-Lassen I, Dahlerup JF, Belard E, et al. Guidelines for screening, prophylaxis and critical information prior to initiating anti TNF-alpha treatment. Dan Med J 2012; 59: 1-12.

6. Kisacık B, Pamuk ON, Onat AM, et al. Characteristics predicting tuberculosis risk under tumor necrosis factor- $\alpha$ inhibitors: report from a large multicenter cohort with high background prevalence. J Rheumatol 2016; 43: 524-9.

7. Doğan C, Kiral N, Comert SS, Fidan A, Caglayan B, Salepci B. Tuberculosis frequency in patients taking TNF alpha blockers. Turk Toraks Derg 2012; 13: 93-8.

8. Sağlık Bakanlığı. Tüberküloz Tanı ve Tedavi Rehberi, 2. Baskı Ankara, Mayıs 2019. pp. 5-27.

9. Hanta I, Ozbek S, Kuleci S, Kocabas A. The evaluation of latent tuberculosis in rheumatologic diseases for anti TNF Therapy: Experience with 192 patients. Clin Rheumatol 2008; 27: 1083-6. Aydın V, Akıcı A, Islı F, Aksoy M, Aydın M, Gürsöz H. Relative risk of tuberculosis in patients with rheumatic diseases managed with anti-tumour necrosis factor-alpha therapy: A nationwide cohort study. J Clin Pharm Ther 2019; 44: 553-60.

10. Chan MJ, Wen YH, Huang YB, et al. Risk of tuberculosis comparison in new users of antitumour necrosis factor- $\alpha$ and with existing disease-modifying antirheumatic drug therapy. J Clin Pharm Ther 2018; 43: 256-64.

11. Askling J, Fored CM, Brandt L, et al. Risk and case characteristics of tuberculosis in rheumatoid arthritis associated with tumor necrosis factor antagonists in Sweden. Arthritis Rheum 2005; 52: 1986-92.

12. Gomez-Reino JJ, Carmona L, Angel DM. Risk of tuberculosis in patients treated with tumor necrosis factor antagonists due to incomplete prevention of reactivation of latent infection. Arthritis Rheum 2007; 57: 756-61.

13. WHO. Global Tuberculosis Report 2017. Geneva, Switzerland: World Health Organization; 2017.

14. Ai JW, Zhang S, Ruan QL, et al. The risk of tuberculosis in patients with rheumatoid arthritis treated with tumor necrosis factor-a antagonist: a meta analysis of both randomized controlled trials and registry/cohort studies. J Rheumatol 2015; 42: 2229-37.

15. Bonovas S, Fiorino G, Allocca M, et al. Biologic therapies and risk of infection and malignancy in patients with inflammatory bowel disease: a systematic review and network meta-analysis. Clin Gastroenterol Hepatol 2016; 14: 1385-97. e10.

16. Ford AC, Peyrin-Biroulet L. Opportunistic infections with anti-tumor necrosis factor- $\alpha$ therapy in inflammatory bowel disease: meta-analysis of randomized controlled trials. Am J Gastroenterol 2013; 108: 1268-76.

17. Cao BL, Qasem A, Sharp RC, Abdelli LS, Naser SA. Systematic review and meta-analysis on the association of tuberculosis in Crohn's disease patients treated with tumor necrosis factor- $\alpha$ inhibitors (Anti-TNFa). World J Gastroenterol 2018; 24: 276475. 
18. Tubach F, Salmon D, Ravaud P, et al. Risk of tuberculosis is higher with anti-tumor necrosis factor monoclonal antibody therapy than with soluble tumor necrosis factor receptor therapy: the three-year prospective French research axed on tolerance of biotherapies registry. Arthritis Rheum 2009; 60: 1884-94.

19. Seong SS, Choi CB, Woo JH, et al. Incidence of tuberculosis in Korean patients with rheumatoid arthritis (RA): effects of RA itself and of tumor necrosis factor blockers. J Rheumatol 2007; 34: 706-11.

20. Sichletidis L, Settas L, Spyratos D, Chloros D, Patakas D. Tuberculosis in patients receiving anti-TNF agents despite chemoprophylaxis. Int J Tuberc Lung Dis 2006; 10: 1127-32.

21. Lee EH, Kang YA, Leem AY, et al. Active tuberculosis incidence and characteristics in patients treated with tumor necrosis factor antagonists according to latent tuberculosis infection. Sci Rep 2017; 7: 6473.

22. Nakagawa M. [Factors for the onset of and the exacerbation of tuberculosis. 4. Clinical factors related to the onset and exacerbation of tuberculosis. b. Middle-aged and elderly patients] Kekkaku. 1999; 74: 747-52.

23. Jadoon SMK, Moin S, Ahmed TA, Bashir MM, Jadoon S. Smearnegative pulmonary tuberculosis and lymphocyte subsets. J Coll Physicians Surg Pak 2004; 14: 419-22.

24. Berhane M,Melku M, Amsalu A, Enawgaw B, Getaneh Z. The role of neutrophil to lymphocyte count ratio in the differential diagnosis of pulmonary tuberculosis and bacterial communityacquired pneumonia: a cross-sectional study at Ayder and Mekelle Hospitals. Clin Lab 2019; 65. 